\title{
DECOMPOSITION OF WETLAND MACROPHYTES AFFECTS THE RELEASE OF HEAVY METALS FROM SEDIMENTS TO THE OVERLYING WATER
}

\author{
FENG, Q. ${ }^{1}-$ HAN, L. ${ }^{2}-$ LOU, Q. ${ }^{2}-$ FU, S. S. ${ }^{2 *}-$ LIU, J. T. ${ }^{2}-$ ZHANG, L. T. $^{2}$ \\ ${ }^{1}$ Nanchang Institute of Technology, Nanchang 330099, People's Republic of China \\ ${ }^{2}$ Jiangxi Institute of Water Sciences, Nanchang 330029, People's Republic of China \\ ${ }^{*}$ Corresponding author \\ e-mail: fushasha1981@163.com
}

(Received $17^{\text {th }}$ Jun 2019; accepted $25^{\text {th }}$ Oct 2019)

\begin{abstract}
The study aimed to examine the effect of the decomposition of macrophyte materials on the release potential of heavy metals $(\mathrm{Zn}, \mathrm{Cu}, \mathrm{Pb}$ and $\mathrm{Cd})$ from the lake sediment to the overlying water. $\mathrm{A}$ laboratory experiment was carried out with a common macrophyte species (Carex cinerascens Kukenth) to examine the effects of macrophyte decomposition on the release of heavy metals $(\mathrm{Cu}, \mathrm{Zn}, \mathrm{Cd}, \mathrm{Pb})$ from the sediment. Fresh aboveground parts of the macrophyte were added to the sediment and the treated sediment was subsequently subjected to a permanent flood condition. Dissolved organic carbon (DOC), $\mathrm{pH}$ and heavy metal concentrations of the overlying water were measured during the 135 -day experiment. In most cases, the rate at which heavy metals were released form the sediments was reduced after the addition of macrophyte biomass. The greater the amount of the macrophyte amendment, the greater the decrease in heavy metals released from the sediment. There is no significant correlation between the DOC concentration in the overlying water and the four heavy metals released from sediments. The addition of macrophyte biomass can reduce the heavy metals release from sediments.
\end{abstract}

Keywords: dissolved organic carbon, Carex cinerascens Kukenth, metal mobility

\section{Introduction}

By acting as a sink of organic matter, wetland sediments generally play a fundamental role in determining the concentration of nutrients in waters (Yuan et al., 2011; Dittrich et al., 2013). However, sediments usually suffer severe levels of heavy metal pollution - up to hundreds of parts per million (Yin, 2011). There are several reports that wetland sediments are heavily contaminated with heavy metals (Kouba et al., 2010; Yuan et al., 2011; Schaller et al., 2013). This results in an enhanced environmental risk for associated ecosystems and organisms, especially as the heavy metals may be at concentrations that are toxic to many species (Nriagu and Pacyna, 1988).

Sediment can become remobilized and release metals into the water column; therefore, sediments area potential source of contamination in wetland environments (Hafeznezami et al., 2012). Some studies have demonstrated that sediments can be a significant source of metal emissions (Chon et al., 2012; Schaller et al., 2013). The sediments most significant for binding metals are thought to be organic matter and $\mathrm{Fe}$ and Mn oxyhydroxides. Recent studies have demonstrated that organic matter in lake sediments can interact with heavy metals to form organometal complexes, and thus can significantly affect various aspects of heavy metals such as form, distribution, biotoxicity, migration and transformation (Yamashita and Jaffe, 2008; Guo et al., 2012). 
In freshwater environments, organic matter is a ubiquitous, naturally occurring, heterogeneous mixture of organic compounds formed from the degradation of ligninrich plant materials and the decay of dead organic biomass. Based on filtration, the organic matter fraction that passes through a $0.45-\mu \mathrm{m}$ membrane is known as the dissolved organic matter (DOM), of which $\geq 50 \%$ by mass is carbon. The concentration of DOM is widely variable in freshwater and commonly reported in $\mathrm{mg}$ $\mathrm{C} \mathrm{L}^{-1}$, as dissolved organic carbon (DOC) (Al-Reasi et al., 2013).

Organic matter in sediments is highly influenced by the primary production in lake ecosystems (Noges et al., 1999). After decaying, the detritus from macrophytes and algal biomass settles into sediments and will eventually be decomposed by the microbial community (Han et al., 2015). Microbial decay of organic matter in sediments is accompanied by the release of DOC into the water (Schaller et al., 2008). DOC is known to complex heavy metals and remains mobile (Sachs et al., 2007; Zhao et al., 2009). Ashworth and Alloway (2008) showed that the solubility of the heavy metals copper $(\mathrm{Cu})$, nickel $(\mathrm{Ni})$, and lead $(\mathrm{Pb})$ in soil have a strong positive relationship to the solubility of organic matter. Soil DOM may increase aqueous heavy metal concentrations by forming metal-DOM aqueous complexes, as demonstrated by Wang and Mulligan (2009). However, Ranville et al. (2007) showed that high DOC levels had no effect on uranium remobilization when the $\mathrm{pH}$ was above 7. Moreover, there are observations that vegetated water bodies and related organic sediments have a higher capacity to immobilize the mobile metals (Dienemann et al., 2006; Ross and Dudel, 2008). Plant litter can provide a metal sink if, during decomposition, metals are bound to the litter by passive sorption on the organic surfaces or by accumulation by microbial colonizers of the litter (Du Laing et al., 2006, 2007; Guo et al., 2006). Accordingly, strong positive correlations have been found between metal concentrations in the sediment and organic matter concentrations in the upper sediment layer of the Scheldt marshes (Du Laing et al., 2007). As a result, the DOC produced during plant decomposition could enhance the mobility of heavy metals in the sediment or soil, but the plant materials could also provide a metal sink. It is unclear which process is dominant.

Therefore, a laboratory experiment was conducted to examine the effect of the decomposition of macrophyte materials (Carex cinerascens Kukenth) on the release potential of heavy metals $(\mathrm{Zn}, \mathrm{Cu}, \mathrm{Pb}$ and $\mathrm{Cd}$ ) from the lake sediment to the overlying water.

\section{Material and methods}

\section{The wetland plant selection and collection}

Carex cinerascens is a good forage grass, and is distributed in Northeast, Northwest, North, East, Central and southwest alpine area of China. It grows on the lake, riverside or marshland.

On April 5th, 2016, the aboveground biomass of $C$. cinerascens was sampled from Xicha Lake located in Gongqingcheng city of Jiangxi province in China. The aboveground parts were harvested and thoroughly washed with deionized water. After allowing most of the water to drip off, the fresh macrophytes were chopped into approximate one-centimetre sections. Chopped plant parts were mixed in order to equalize any differences in the composition of various plant organs, the variability in their decomposition rates, and the resultant activity of microbial decomposers. 


\section{The wetland sediment collection and treatment}

Surface sediment samples $(0-10 \mathrm{~cm})$ were collected from Xicha Lake located in Gongqingcheng city in December 2014 during the dry season. Upon return to the laboratory, the sediment was air dried and sieved through a 2-mm mesh nylon sieve. Heavy metals were added to the sediment in the form of $\mathrm{CuSO}_{4} \cdot 5 \mathrm{H}_{2} \mathrm{O}, \mathrm{ZnCl}_{2}$, $\mathrm{CdSO}_{4} \cdot 8 / 3 \mathrm{H}_{2} \mathrm{O}$ and $\mathrm{Pb}\left(\mathrm{NO}_{3}\right)_{2}$. The sediment was increased artificially to reach final values of $394 \mathrm{mg} \cdot \mathrm{kg}^{-1}$ of $\mathrm{Cu}, 775 \mathrm{mg} \cdot \mathrm{kg}^{-1}$ of $\mathrm{Zn}, 7 \mathrm{mg} \cdot \mathrm{kg}^{-1}$ of Cd and $352 \mathrm{mg} \cdot \mathrm{kg}^{-1}$ of $\mathrm{Pb}$ for the low levels of heavy metal contamination (LS), and $691 \mathrm{mg} \cdot \mathrm{kg}^{-1}$ of $\mathrm{Cu}$, $1445 \mathrm{mg} \cdot \mathrm{kg}^{-1}$ of $\mathrm{Zn}, 12 \mathrm{mg} \cdot \mathrm{kg}^{-1}$ of $\mathrm{Cd}$ and $596 \mathrm{mg} \cdot \mathrm{kg}^{-1}$ of $\mathrm{Pb}$ for the high levels of heavy metal contamination (HS). The sediment was then placed in a plastic bucket and watered well. After 16 months, the sediment was sieved through a $2 \mathrm{~mm}$ mesh nylon sieve and was subjected to laboratory-scale incubation experiments. Table 1 reports selected characteristics of the sediment used in the experiment.

Table 1. Physical and chemical properties of the two levels of heavy metal contamination

\begin{tabular}{c|cccccc|c|c}
\hline \multirow{2}{*}{ Parameters } & $\mathbf{C u}$ & $\mathbf{Z n}$ & $\mathbf{C d}$ & $\mathbf{P b}$ & $\mathbf{C a}$ & $\mathbf{M g}$ & TC & \multirow{2}{*}{$\mathbf{p H}$} \\
\cline { 2 - 8 } & \multicolumn{7}{|c}{$\mathrm{mg} \mathrm{kg}^{-1}$} \\
LS & 394 & 775 & 7 & 352 & 4911 & 4269 & 0.46 & 5.50 \\
HS & 691 & 1445 & 12 & 596 & 5186 & 4597 & 0.48 & 5.54 \\
\hline
\end{tabular}

LS and HS represent the low and high levels of heavy metal contamination in the sediment, respectively

\section{The overlying water used in the experiment}

On April 5th, 2016, water was collected from Xicha Lake located in Gongqingcheng city, where the water quality is relatively good. After being transported to the laboratory, the collected lake water was filtered immediately through a $0.45-\mu \mathrm{m}$ membrane and stored at $4^{\circ} \mathrm{C}$ for the experiment. The $\mathrm{pH}$ of the lake water was 6.94. The concentrations of $\mathrm{Cu}, \mathrm{Zn}, \mathrm{Cd}, \mathrm{Pb}, \mathrm{Ca}$ and $\mathrm{Mg}$ in the lake water were $0.656 \mu \mathrm{gL}^{-1}, 4.980$ $\mu \mathrm{gL}^{-1}, 0.533 \mu \mathrm{gL}^{-1}, 0.385 \mu \mathrm{gL}^{-1}, 27461 \mu \mathrm{gL}^{-1}$ and $3038 \mu \mathrm{gL}^{-1}$, respectively.

\section{Experimental conditions and design}

To investigate the effects of the decomposition of the aboveground parts of C. cinerascens in flooding season on the release of heavy metals from the sediment, two levels of macrophyte biomass additions were used in the experiment. One level is $17 \mathrm{~g}$ of fresh weight, which represents the macrophyte biomass in the spring in the field, and the other is $7 \mathrm{~g}$ fresh weight. For the experiment with sediments, there were six treatments: LS+water, LS+7 g macrophyte+water, LS+17 g macrophyte+water, $\mathrm{HS}+$ water, $\mathrm{HS}+7 \mathrm{~g}$ macrophyte+water, and $\mathrm{HS}+17 \mathrm{~g}$ macrophyte+water. In addition, two treatments without sediments were included: $7 \mathrm{~g}$ macrophyte+water and, $17 \mathrm{~g}$ macrophyte+water. In total, eight treatments were conducted with each treatment performed in triplicate. The sediment+water and sediment+macrophyte+water treatments were used to test the effect of plant decomposition on the release of heavy metals from the sediments. The macrophyte+water treatment was used to determine the amount of heavy metal release from the plant itself to the overlying water. 
The release experiments were performed in 2.0-L glass beakers $13.3 \mathrm{~cm}$ in diameter and $19.3 \mathrm{~cm}$ in height, and the beakers were side-wrapped in black plastic to avoid light exposure. First, $300 \mathrm{~g}$ of air-dried sediment were put into the bottom of the vessel, and mixed with increasing amounts of chopped fresh plant weight. Finally, $1.5 \mathrm{~L}$ of filtered lake water was added into each beaker. All experiments were conducted at the laboratory with no temperature control from April 5th to August 18th, 2016, and the incubation lasted 135 days. During the experimental period, water samples were taken (after 1, 4, 11, 18, 32, 90 and 135 days) from each vessel with a pipette at a depth of $5 \mathrm{~cm}$ above the sediment-water interface for the heavy metal and DOC analysis, and then the $\mathrm{pH}$ of the overlying water was determined. Before the first day of the sampling, the evaporated water was added and after the sampling, $20 \mathrm{ml}$ of deionized water was added to supplement the sampling water. For heavy metal analysis, the 10-ml sample was centrifuged immediately after sampling and acidified with $\mathrm{HNO}_{3}$. For the determination of dissolved organic carbon (DOC), $10 \mathrm{ml}$ of water was sampled using PE (polyethylene) vessels, filtered using $0.45-\mu \mathrm{m}$ celluloseacetate filters and immediately measured.

\section{Analytical methods}

The element concentrations were analysed at the analytical laboratory of the Beijing Research Institute of Uranium Geology, which is registered to the China National Accreditation Service for Conformity Assessment and the China Metrology Accreditation system, using an inductively coupled plasma mass spectrometer (PerkinElmer Elan DRC-e, American). The DOC of the water samples was determined using a TOC analyser (Tekmar Torch, American). Carbon content in the sediment samples was measured with an element analyser (ElementarVario Macro Cube, Germany). The $\mathrm{pH}$ of the overlying water was determined using a $\mathrm{pH}$ meter (Leici PHSJ-3F, Shanghai) and the $\mathrm{pH}$ of the sediment was also determined by a $\mathrm{pH}$ meter according to the Standard of the Ministry of Agriculture of the People's Republic of China (NY/T 1377-2007).

\section{Statistical analysis}

The percent decrease of the concentration of metal $X$ in overlying water at time $t$ after addition of macrophytes $\left(P D_{t}\right)$ was calculated according to the following formula:

$$
P D_{t}(\%)=\frac{X_{\mathrm{t} 0}\left(m g L^{-1}\right)-X_{t p}\left(m g L^{-1}\right)}{X_{\mathrm{t} 0}\left(m g L^{-1}\right)} \times 100
$$

where $P D_{t}$ is the decreased percentage of metal $X$ concentration in the overlying water after the addition of the macrophyte; $X_{t 0}$ is the metal $X$ concentration in the overlying water with no addition of the macrophyte at time $t$; and $X_{t p}$ is the metal $X$ concentration in the overlying water after addition of the macrophyte at time $t . \mathrm{PD}_{\mathrm{t}}<0$ indicates a net increase of metal ' $X$ ' released from the sediment by the decaying plant, while $\mathrm{PD}_{\mathrm{t}}>0$ indicates a net decrease of metal ' $X$ ' released by the decaying plant.

For each heavy metal pollution level, differences in the measured parameters among three treatments were tested by a one-way analysis of variance (ANOVA) followed by Tukey's post hoc analysis when appropriate. A correlation analysis (Pearson's correlation coefficients) was used to test the relationships between DOC and heavy metal concentration during the 135-day period. Differences in the percentage decrease of the heavy metal concentration in overlying water after the macrophyte biomass 
addition, between the earlier stage of the experiment (treatments for 1 day, 4 days and 11 days) and the later stage (treatments for 18 days, 32 days, 90 days and 135 days), were tested with a paired samples test. All statistical analyses were performed using the SPSS 11.5 software package.

\section{Results}

\section{Dynamic changes in pH and DOC concentration in overlying water}

The $\mathrm{pH}$ of the overlying water was significantly decreased by the macrophyte addition on the first day and then increased by the macrophyte addition (Fig. 1). However, there were no significant differences in $\mathrm{pH}$ between the sediment+water+7 $\mathrm{g}$ macrophyte treatment and the sediment+water $+17 \mathrm{~g}$ macrophyte treatments $(\mathrm{p}>0.05)$. And there were no significant differences in $\mathrm{pH}$ between the two treatments with low and high concentrations of heavy metals in sediments ( $>>0.05)$ and the $\mathrm{pH}$ values shown in Fig. 1 were the average of the treatments with low and high concentrations of heavy metal in sediments.

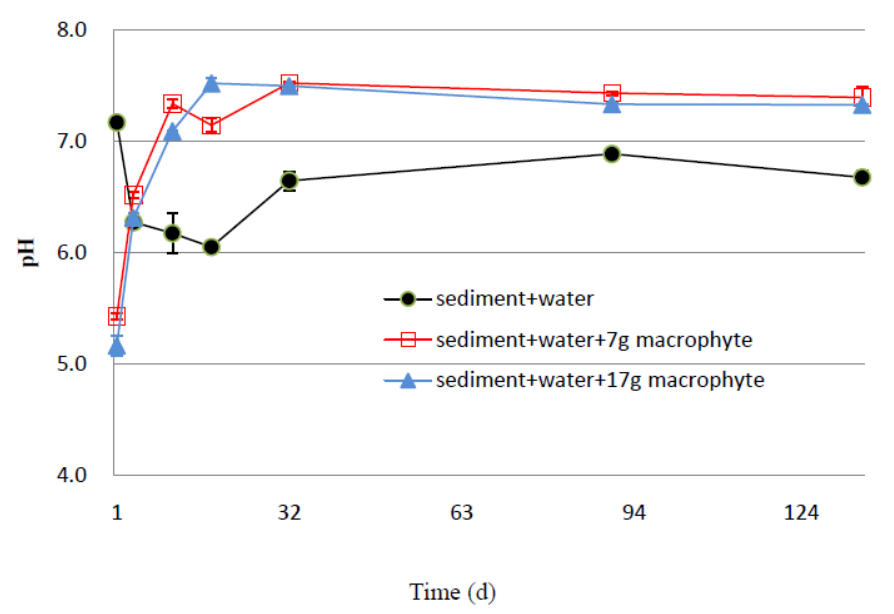

Figure 1. Change in $p H$ value of overlying water during the C. cinerascens amendment. The $p H$ values shown in the figure were the average of the treatments with low and high concentrations of heavy metal in sediments

The DOC concentrations of the overlying water in the treatments with macrophyte biomass amendments increased remarkably, and showed similar variation during the 135-day decomposition process (Fig. 2). For the treatments with low and high levels of heavy metal contamination in sediments, the DOC concentrations in treatments with the macrophyte addition increased with time and peaked around day 4 and day 11, and then decreased or remained relatively stable. In addition, the mean DOC concentrations followed the order: sediment+water $+17 \mathrm{~g}$ macrophyte $>$ sediment+water $+7 \mathrm{~g}$ macrophyte >sediment+water (Fig. 2a,b). Within the treatments with the same amount of macrophyte biomass addition, there were no significant differences in DOC concentrations between the two treatments with low and high concentrations of heavy metal in sediments ( $p>0.05)$. DOC concentrations ranged from $0.47-5.05 \mathrm{mgL}^{-1}$ in the sediment treatments, $1.5-21.27 \mathrm{mgL}^{-1}$ in the sediment+water+7 $\mathrm{g}$ macrophyte treatment and $0.65-50.82 \mathrm{mgL}^{-1}$ in the sediment+water $+17 \mathrm{~g}$ macrophyte treatments. 

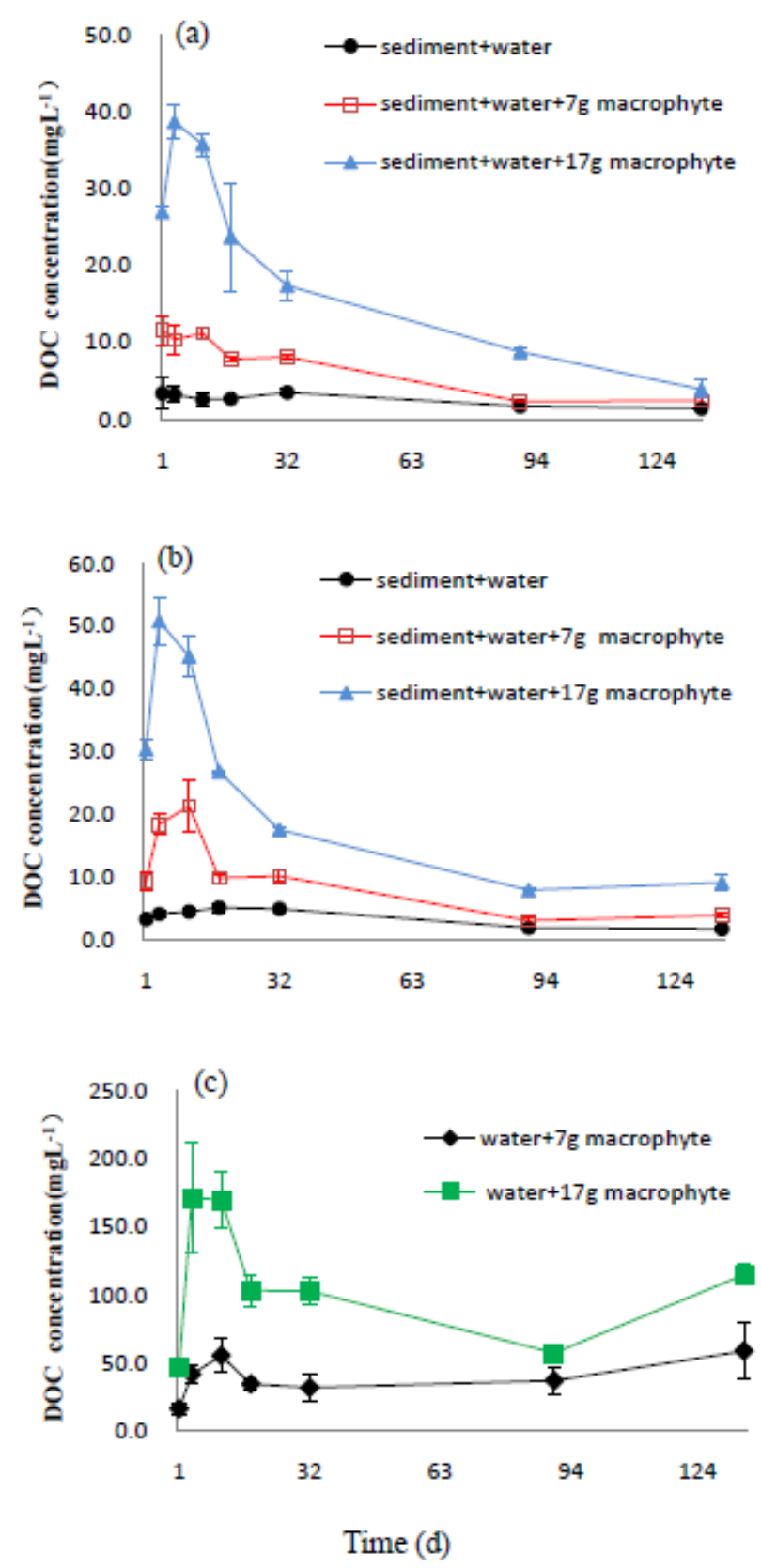

Figure 2. Change in DOC concentrations in overlying water during the C. cinerascens amendment. (a) The treatments with low concentrations of heavy metal in sediments; (b)the treatments with high concentrations of heavy metal in sediments; (c) the treatments without sediments, as a function of time after flooding. Error bars indicate standard deviations

However, DOC concentrations in the water+macrophyte treatment were significantly higher than in the sediment+water+macrophyte treatments with the same amount of macrophyte biomass added $(\mathrm{p}<0.05)$. DOC concentrations in the water $+7 \mathrm{~g}$ macrophyte treatments ranged from 15.93-58.49 $\mathrm{mgL}^{-1}$ and from $45.83-171.75 \mathrm{mgL}^{-1}$ in the water $+17 \mathrm{~g}$ macrophyte treatment. However, for the water+macrophyte treatments, DOC concentrations increased during the first few days, then declined, and increased at a later stage. 


\section{The effect of macrophyte addition on the release of heavy metals from sediments}

Dynamic changes in heavy metal concentration of the overlying water

For the water+macrophyte treatments, the concentrations of four heavy metals in the water body were very low, at several parts per billion. Thus, the effect of heavy metals released by the macrophyte itself into the overlying water is negligible in the sediment+water+macrophyte treatment (Fig. 3c, Fig. 4c, Fig. 5c, and Fig. 6c).
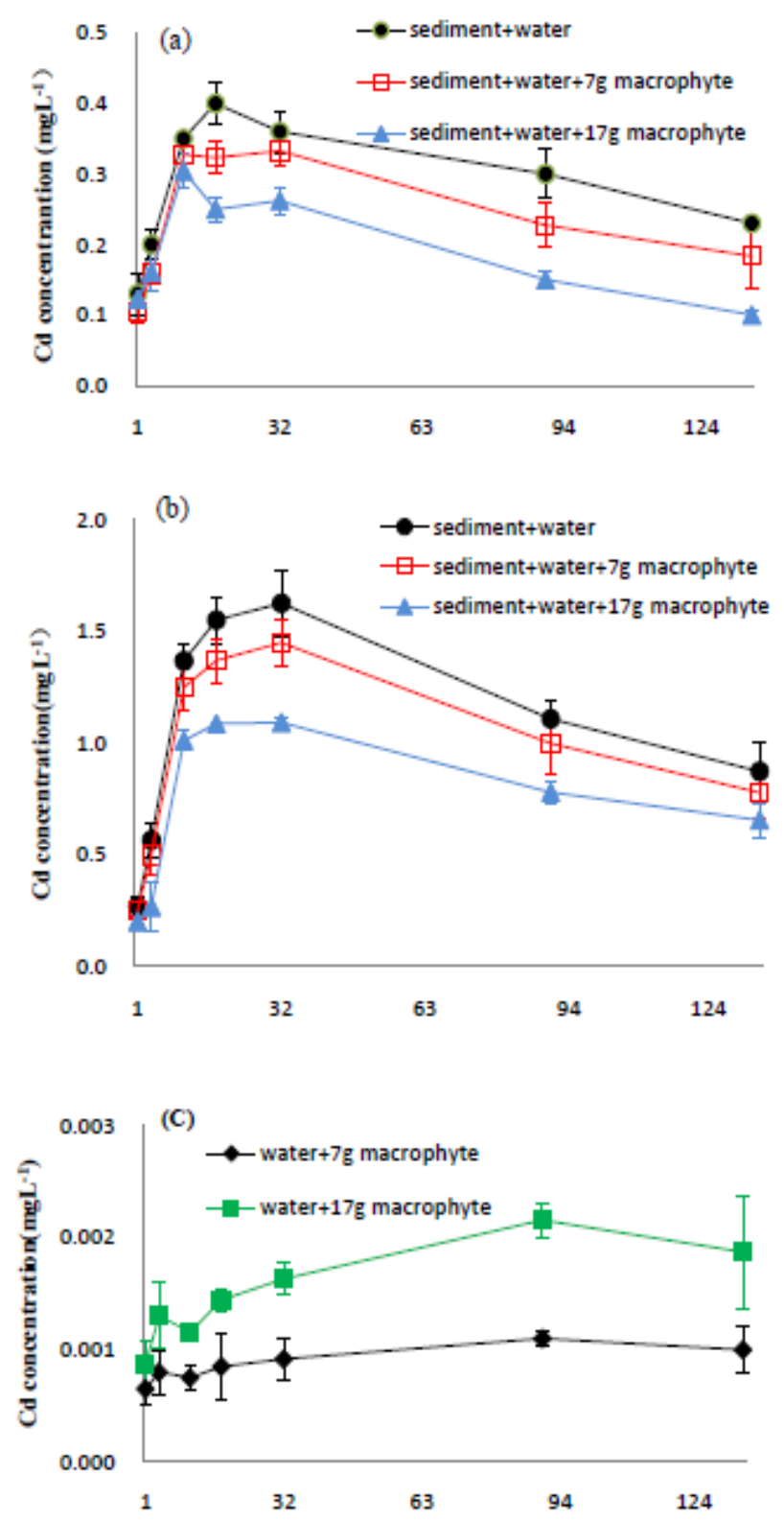

Time (d)

Figure 3. Changes in Cd concentrations in overlying water during the C. cinerascens amendment. (a)The treatments with low concentrations of heavy metal in sediments; $(b)$ the treatments with high concentrations of heavy metal in sediments; $(c)$ the treatments without sediments, as a function of time after flooding. Error bars indicate standard deviations 


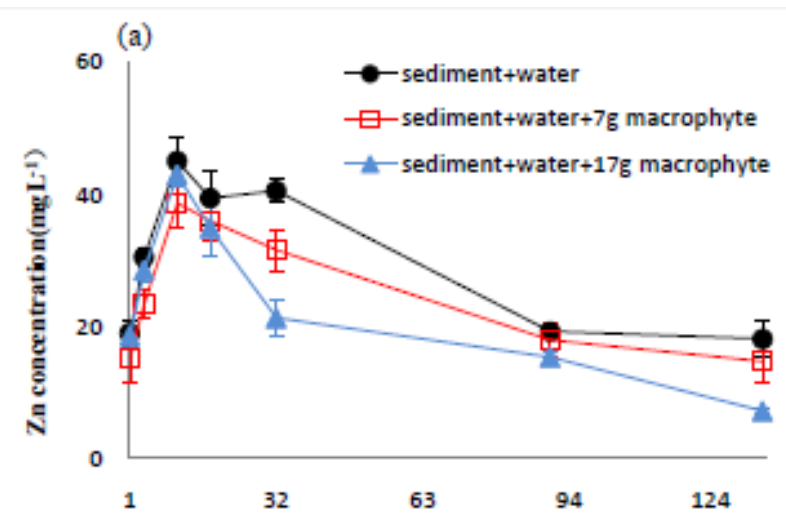

(b)
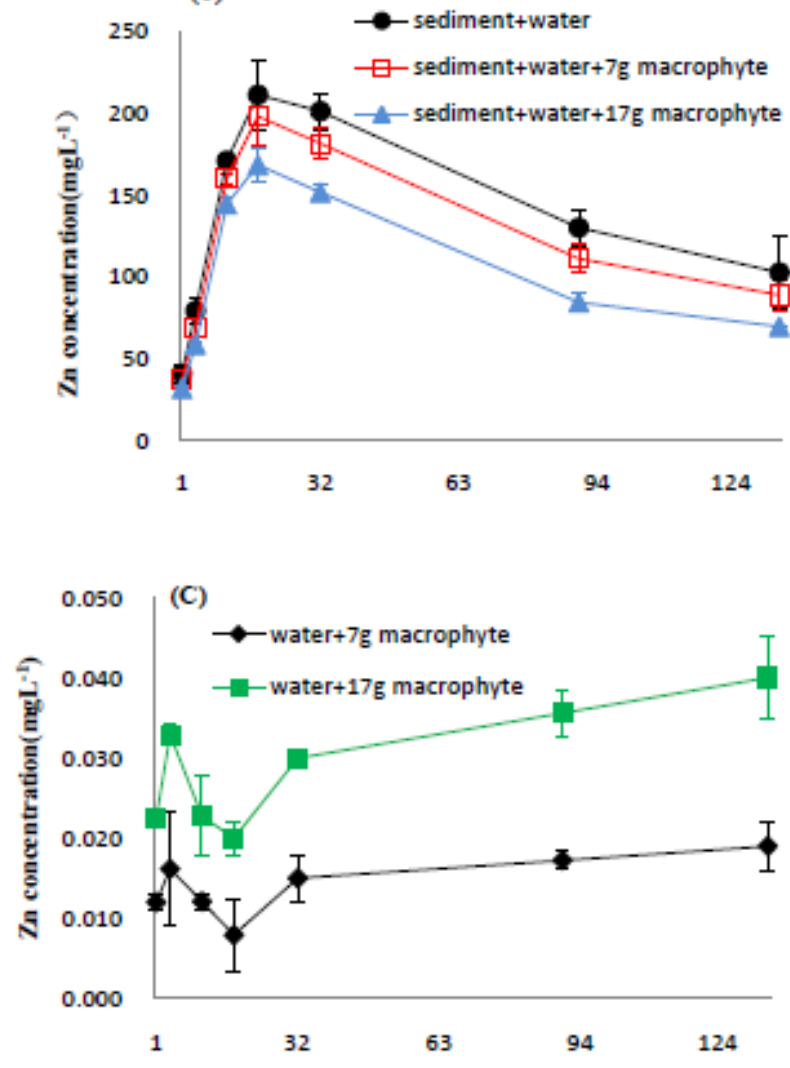

Time (d)

Figure 4. Changes in Zn concentrations in overlying water during the C. cinerascens amendment. (a)The treatments with low concentrations of heavy metal in sediments; $(b)$ the treatments with high concentrations of heavy metal in sediments; $(c)$ the treatments without sediments, as a function of time after flooding. Error bars indicate standard deviations

The release of four kinds of heavy metals in the sediments was not the same, as a function of time after flooding. However, in general, in the later stage of the experiment, the mean concentrations of $\mathrm{Cd}, \mathrm{Zn}, \mathrm{Cu}$ and $\mathrm{Pb}$ in the overlying water followed the order: sediment+water $>$ sediment+water $+7 \mathrm{~g}$ macrophyte $>$ sediment+water+17 g macrophyte.

For both levels of heavy metal contamination in the sediment, $\mathrm{Cd}$ and $\mathrm{Zn}$ concentrations in the overlying water first increased with time and then decreased. In general, the effect of 
the macrophyte addition on the release of heavy metals from sediment was not obvious in the early stage of the experiment, but in the later stage, the macrophyte addition could significantly reduce the release of heavy metals from sediment to the overlying water $(\mathrm{p}<0.05)$. In general, the mean $\mathrm{Cd}$ and $\mathrm{Zn}$ concentrations in the overlying water followed the order: sediment+water $>$ sediment+water $+7 \mathrm{~g}$ macrophyte $>$ sediment+water $+17 \mathrm{~g}$ macrophyte (Fig. 3a,b and Fig. 4a,b).
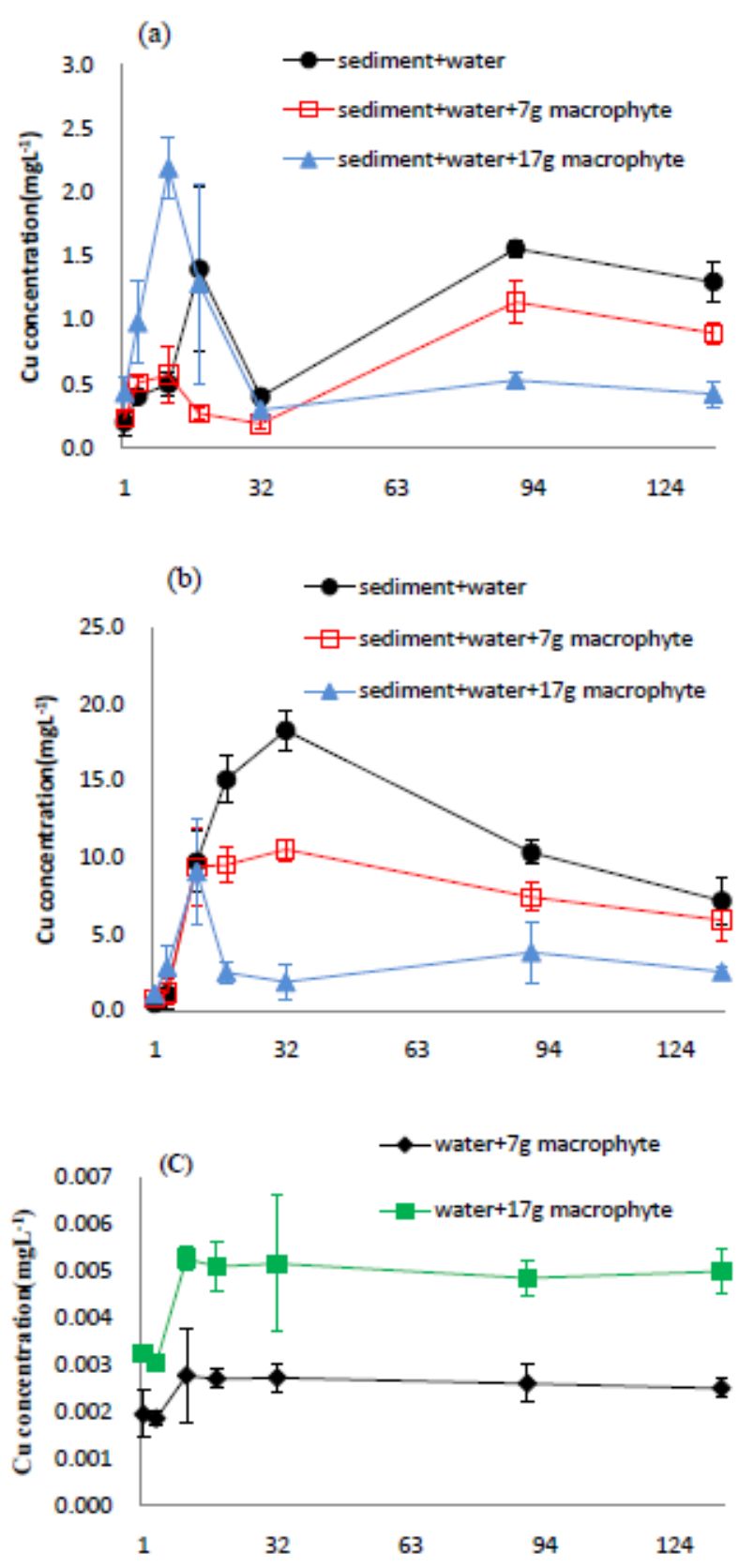

Time (d)

Figure 5. Changes in Cu concentrations in overlying water during the C. cinerascens amendment. (a) The treatments with low concentrations of heavy metal in sediments; (b) the treatments with high concentrations of heavy metal in sediments; (c) the treatments without sediments, as a function of time after flooding. Error bars indicate standard deviations 

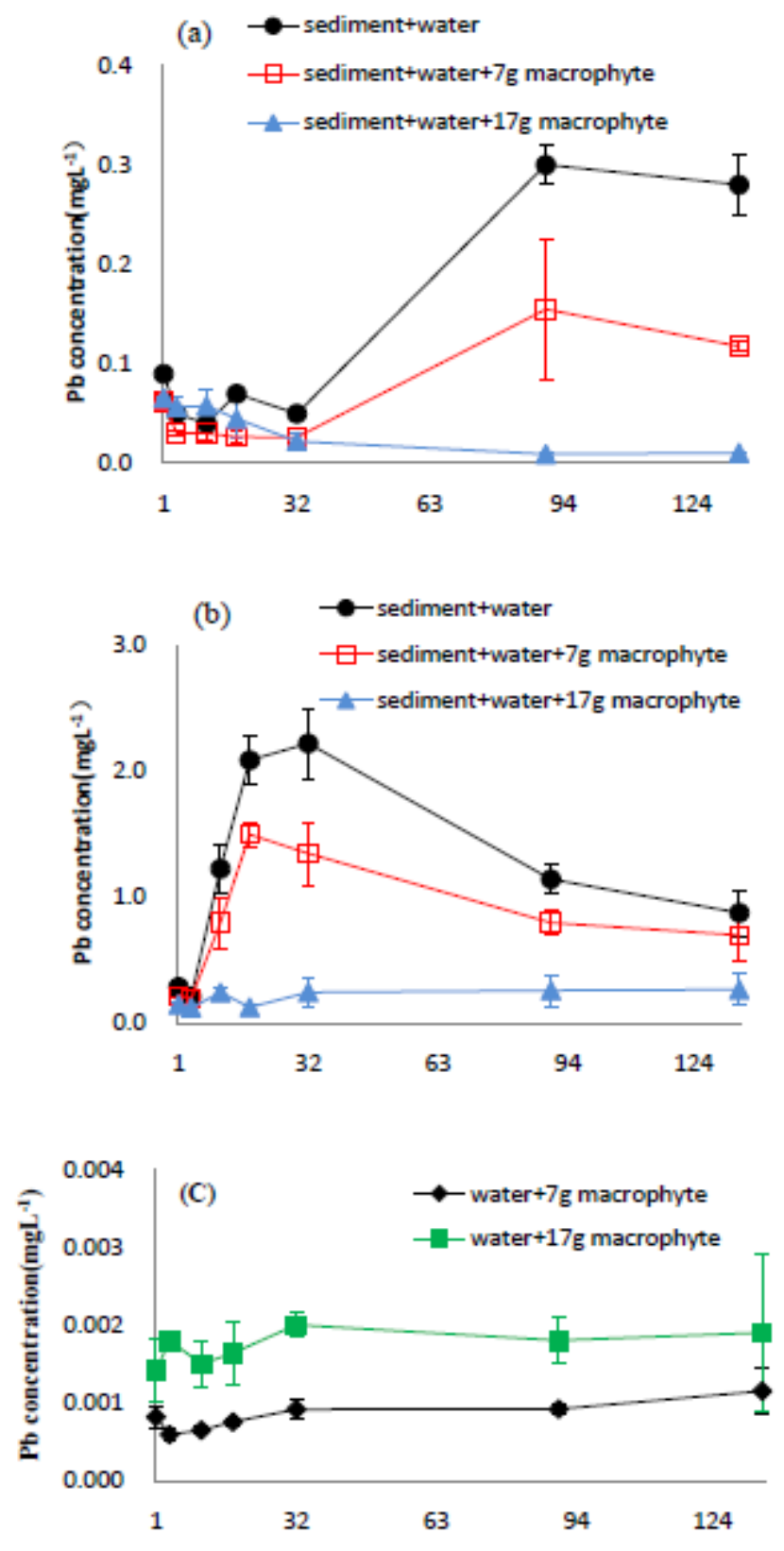

Time (d)

Figure 6. Changes in Pb concentrations in overlying water during the C. cinerascens amendment. (a) The treatments with low concentrations of heavy metal in sediments; $(b)$ the treatments with high concentrations of heavy metal in sediments; (c) the treatments without sediments, as a function of time after flooding. Error bars indicate standard deviations

The release of $\mathrm{Cu}$ and $\mathrm{Pb}$ were slightly different from $\mathrm{Cd}$ and $\mathrm{Zn}$, as a function of time after flooding. At low levels of heavy metal sediment contamination, both the $\mathrm{Cu}$ and $\mathrm{Pb}$ concentrations in the overlying water began to increase after 32 days, and the macrophyte addition significantly reduced the metal concentrations in the overlying water $(\mathrm{p}<0.05)$. At high levels of heavy metal contamination, the $\mathrm{Cu}$ and $\mathrm{Pb}$ 
concentrations in the overlying water first increased, then decreased and tended to be stable. At the two levels of heavy metal sediment contamination, the mean $\mathrm{Cu}$ and $\mathrm{Pb}$ concentrations in the later stage of the experiment followed the order: sediment+water> sediment+water+7 g macrophyte $>$ sediment+water+17 g macrophyte (Fig. 5a,b and Fig. $6 a, b$ ). Moreover, the heavy metal concentration in the overlying water was significantly lower in the treatments with $17 \mathrm{~g}$ macrophyte addition than without macrophyte addition $(\mathrm{p}<0.05)$.

The decreased heavy metal concentrations in overlying water after the plant biomass addition to the sediment

To investigate the effect of the macrophyte biomass addition on the release of heavy metals from the sediments, $\mathrm{PD}_{\mathrm{t}}(\%)$ was calculated according to $E q$. (1), and the results are shown in Table 2. It was found that the $\mathrm{PD}_{\mathrm{t}}(\%)$ values of $\mathrm{Cd}$ and $\mathrm{Zn}$ were all greater than zero. With low levels of heavy metal contamination in sediments, the $\mathrm{Cd}$ and $\mathrm{Zn}$ concentrations in the overlying water were decreased $6 \%-20 \%$ and $7 \%-23 \%$, respectively, with the7 $\mathrm{g}$ macrophyte biomass addition, and 6\%-57\% and $2-60 \%$, respectively, with the $17 \mathrm{~g}$ macrophyte biomass addition.

Table 2. The decreased percentage of heavy metal concentration in overlying water after addition of plant biomass

\begin{tabular}{|c|c|c|c|c|c|c|c|}
\hline Treatment & 1d & $4 d$ & 11d & 18d & 32d & 90d & 135d \\
\hline \multicolumn{8}{|c|}{ Cd } \\
\hline LS+water+7g macrophyte & 19 & 21 & 6 & 19 & 8 & 24 & 20 \\
\hline LS+water $+17 \mathrm{~g}$ macrophyte & 6 & 20 & 13 & 38 & 27 & 50 & 57 \\
\hline HS+water+7g macrophyte & 8 & 12 & 9 & 12 & 11 & 10 & 11 \\
\hline HS+water+7g macrophyte & 26 & 53 & 26 & 30 & 33 & 30 & 25 \\
\hline \multicolumn{8}{|c|}{ Zn } \\
\hline LS+water+7g macrophyte & 20 & 23 & 14 & 9 & 22 & 7 & 19 \\
\hline LS+water $+17 \mathrm{~g}$ macrophyte & 2 & 7 & 5 & 12 & 48 & 20 & 60 \\
\hline HS+water+7g macrophyte & 10 & 13 & 6 & 6 & 10 & 14 & 13 \\
\hline HS+water+7g macrophyte & 23 & 26 & 15 & 20 & 25 & 35 & 32 \\
\hline \multicolumn{8}{|c|}{$\mathrm{Cu}$} \\
\hline LS+water+7g macrophyte & -18 & -28 & -14 & 81 & 53 & 27 & 31 \\
\hline LS+water $+17 \mathrm{~g}$ macrophyte & -115 & -145 & -338 & 8 & 26 & 66 & 68 \\
\hline HS+water+7g macrophyte & -65 & -12 & 3 & 37 & 43 & 28 & 18 \\
\hline HS+water+7g macrophyte & -128 & -163 & 7 & 84 & 90 & 63 & 65 \\
\hline \multicolumn{8}{|c|}{$\mathbf{P b}$} \\
\hline LS+water+7g macrophyte & 31 & 39 & 24 & 62 & 48 & 48 & 58 \\
\hline $\mathrm{LS}+$ water $+17 \mathrm{~g}$ macrophyte & 27 & -13 & -45 & 36 & 55 & 97 & 96 \\
\hline HS+water+7g macrophyte & 24 & 6 & 35 & 28 & 39 & 30 & 20 \\
\hline HS+water+7g macrophyte & 48 & 42 & 80 & 94 & 89 & 77 & 69 \\
\hline
\end{tabular}

With high levels of heavy metal contamination in sediments, the $\mathrm{Cd}$ and $\mathrm{Zn}$ concentrations in the overlying water were decreased $8 \%-12 \%$ and $6 \%-14 \%$, respectively, with the $7 \mathrm{~g}$ macrophyte biomass addition, and $26 \%-53 \%$ and $15 \%-35 \%$, respectively, with the $17 \mathrm{~g}$ macrophyte biomass addition. The $\mathrm{PD}_{\mathrm{t}}(\%)$ values of $\mathrm{Cu}$ and 
$\mathrm{Pb}$ were all greater than zero in the late stage of the experiment. At low levels of heavy metal contamination in sediments, the $\mathrm{Cu}$ and $\mathrm{Pb}$ concentrations in the overlying water were decreased $27 \%-81 \%$ and $7 \%-23 \%$, respectively, with the $7 \mathrm{~g}$ macrophyte biomass addition, and $6 \%-57 \%$ and $2 \%-60 \%$, respectively, with the $17 \mathrm{~g}$ macrophyte biomass addition. The $\mathrm{PD}_{\mathrm{t}}(\%)$ values of $\mathrm{Cu}$ were less than 0 in the early stage, indicating that the addition of the macrophyte biomass promoted $\mathrm{Cu}$ release, but in the later stage of the experiment, the macrophyte biomass addition significantly reduced the release of $\mathrm{Cu}$, reaching a maximum of $90 \%$. For $\mathrm{Pb}$, the addition of the macrophyte biomass reduced the release of $\mathrm{Pb}$ by up to $97 \%$. The macrophyte additions have greater decreasing effects on the release of $\mathrm{Pb}$ and $\mathrm{Cu}$ than on the release of $\mathrm{Cd}$ and $\mathrm{Zn}$.

There were no significant differences in the percentage of $\mathrm{Cd}$ and $\mathrm{Zn}$ concentrations in the overlying water in the macrophyte biomass addition treatments between the earlier stage and the later stage of the experiment $(p>0.05)$. The decreased concentrations of $\mathrm{Cu}$ and $\mathrm{Pb}$ in the overlying water of the macrophyte biomass addition treatment in the later stages of the experiment were significantly higher than in the earlier stages of the experiment $(\mathrm{p}<0.01$ and $\mathrm{p}<0.05$, respectively).

\section{Correlation between DOC and heavy metal release to the overlying water}

The DOC concentration in the overlying water was tested for correlations with heavy metal concentrations in order to determine the share of metals bound directly to the DOC. With low levels of heavy metal contamination in sediments, DOC had a significantly negative correlation with $\mathrm{Pb}$ concentration $\left(\mathrm{R}^{2}=-0.284, \mathrm{p}<0.01\right)$. No correlations between DOC concentration and $\mathrm{Cd}, \mathrm{Zn}$ and $\mathrm{Cu}$ concentrations were observed. With high levels of heavy metal contamination in sediments, DOC had a significantly negative correlation with the $\mathrm{Cd}$ and $\mathrm{Pb}$ concentrations $\left(\mathrm{R}^{2}=-0.266\right.$ and 0.443 , respectively, $\mathrm{p}<0.01)$. No correlation between the DOC concentration and the $\mathrm{Zn}$ and $\mathrm{Cu}$ concentrations was observed.

\section{Discussion}

DOC is released during plant litter decomposition, when soluble polymeric organic substances are released into the water in the form of dissolved carbon (Bonanomi et al., 2014). The ability of DOC to bind metals during transport through water or soil and to form stable, aqueous complexes with copper, nickel, zinc and other ions has been shown in numerous works (Li and Shuman, 1997; Refaey et al., 2017). However, in this study, there were no significant positive correlations between the DOC concentration in the overlying water and the four heavy metals released from sediments. Some results also report that total dissolved metal concentrations $(\mathrm{Cd}, \mathrm{Zn}, \mathrm{Cu}, \mathrm{Pb}, \mathrm{Co}, \mathrm{Mn}, \mathrm{Ni})$ generally did not show any significant or systematic correlation with DOC concentrations in river waters of Texas, and concluded that natural organic matter complexation was generally not a major process controlling trace metal concentrations (Jiann et al., 2013). Our results are also in accordance with other studies revealing an impact of invertebrate shredders on metal (calcium, manganese, iron, copper, zinc, arsenic, lead) fixation/remobilization with no influence on the DOC level (Schaller et al., 2010, 2013).

The releases of $\mathrm{Cd}, \mathrm{Zn}, \mathrm{Cu}$ and $\mathrm{Pb}$ from sediments were not identically affected by the fresh macrophyte biomass amendments. In most cases, the greater the amount of the plant biomass amendment, the greater the decrease in heavy metals released from 
sediment to the overlying water. It was demonstrated that in the process of plant litters decomposition, metals are combined with litters through passive adsorption on organic surfaces or accumulated by microbial colonizers of the litter. And then plant litters can be places for metal sink (Du Laing et al., 2006, 2007; Guo et al., 2006). Therefore, studies have shown a strong positive correlation between the concentration of metal in the sediment and the concentration of organic matter in the upper sediment layer of the Scheldt marshes (Du Laing et al., 2007). The negative correlation and lack of correlation between the formation of DOC and the release of heavy metals in this study may be attributed to the fact that heavy metals were strongly bound to solid biomass and other colloids fixed on larger fractions but neither attached nor adsorbed the DOC (Schaller et al., 2010).

\section{Conclusion}

This study aimed to investigate the effects of the decomposition of macrophyte materials on heavy metals released from the lake sediment to the overlying water. In conclusion, wetland macrophytes could reduce the release of heavy metals from sediments to the overlying water. The release of heavy metals was not affected by DOC and the plant material may act as a metal sink.

The control of plant harvest or the stimulation of plant biomass production could be considered as management techniques to reduce the mobility of heavy metals in wetland ecosystems. Nevertheless, it is important to note that besides DOC and $\mathrm{pH}$, the effects of decomposing plant materials on environmental conditions, such as electrolytic conductivity, dissolved oxygen and decomposition rate, are not considered in this study. Moreover, more investigations are necessary to understand the mechanisms and the fate of immobilized heavy metals after further decomposition.

Acknowledgements. This work was supported by the Natural Science Foundation of China (Nos.51409133, 51369011), the science and technology projects of the Jiangxi Provincial Department of Water Resources (KT201302, KT201510, KT201605, KT201712, 201820YBKT09) and the open fund of the Poyang Lake Water Resources, Water Ecology and Environment Research Center, MWR (KFJJ201404, ZXKT201701).

\section{REFERENCES}

[1] Al-Reasi, H. A., Wood, C. M., Smith, D. S. (2013): Characterization of freshwater natural dissolved organic matter (DOM): Mechanistic explanations for protective effects against metal toxicity and direct effects on organisms. - Environ Int 59: 201-207.

[2] Ashworth, D. J., Alloway, B. J. (2008): Influence of dissolved organic matter on the solubility of heavy metals in sewage-sludge-amended soils. - Commun Soil Sci Plant Anal 39: 538-550.

[3] Bonanomi, G., Senatore, M., Migliozzi, A., Marcob, A. D., Pintimallic, A., Lanzottia, V., Mazzolenia, S. (2014): Decomposition of submerged plant litter in a Mediterranean reservoir: A microcosm study. - Aquat Bot 120: 169-177.

[4] Chon, H., Ohandja, D., Voulvoulis, N. (2012): The role of sediments as a source of metals in river catchments. - Chemosphere 88: 1250-1256.

[5] Dienemann, H., Dienemann, C., Dudel, E. G. (2006): Influence of allochthonous plant litter on fixation of uranium in sediments. - In: Merkel, B., Hasche-Berger, A. (eds.) Uranium in the Environment. Springer, Berlin, pp. 149-157. 
[6] Dittrich, M., Chesnyuk, A., Gudimov, A., McCulloch, J., Quazi, S., Young, J., Winter, J., Stainsby, E., Arhonditsis, G. (2013): Phosphorus retention in a mesotrophic lake under transient loading conditions: insights from a sediment phosphorus binding form study. Water Resour 47: 1433-1447.

[7] Du Laing, G. (2006): Dynamics of heavy metals in reedbeds along the banks of the river Scheldt. - PhD thesis, Ghent University.

[8] Du Laing, G., De Grauwe, P., Moors, W., Vandecasteele, B., Lesage, E., Meers, E., Tack, F. M. G., Verloo, M. G. (2007): Factors affecting metal concentrations in the upper sediment layer of intertidal reedbeds along the river Scheldt. - Journal of Environ Monit 9: 449-455.

[9] Gessner, M. O. (2000): Breakdown and nutrient dynamics of submerged Phragmites shoots in the littoral zone of a temperate hardwater lake. - Aquat Bot 66: 9-20.

[10] Guo, X. Y., Zhang, S. Z., Shan, X. Q., Luo, L., Pei, Z. G., Zhu, Y. G., Liu, T., Xie, Y. N., Gault, A. (2006): Characterization of $\mathrm{Pb}, \mathrm{Cu}$, and $\mathrm{Cd}$ adsorption on particulate organic matter in soil. - Environ Toxicol Chem 25: 2366-2373.

[11] Guo, X. J., Yuan, D. H., Li, Q., Jiang, J. Y., Chen, F. X., Zhang, H. (2012): Spectroscopic techniques for quantitative characterization of $\mathrm{Cu}$ (II) and $\mathrm{Hg}$ (II) complexation by dissolved organic matter from lake sediment in arid and semiarid region. - Ecotoxicol Environ Saf 85: 144-150.

[12] Hafeznezami, S., Kim, J. L., Redman, J. (2012): Evaluating removal efficiency of heavy metals in constructed wetlands. - J Environ Eng 138(4): 475-482.

[13] Han, Z., Cui, B. S., Zhang, Y. T. (2015): Decomposition of Phragmites australis rhizomes in artificial land-water transitional zones (ALWTZs) and management implications. Frontiers of Earth Science 9(3): 555-566.

[14] Jiann, K., Santschi, P. H., Presley, B. J. (2013): Relationships between geochemical parameters (pH, DOC, SPM, EDTA concentrations) and trace metal $(\mathrm{Cd}, \mathrm{Co}, \mathrm{Cu}, \mathrm{Fe}, \mathrm{Mn}$, $\mathrm{Ni}, \mathrm{Pb}, \mathrm{Zn}$ ) concentrations in river waters of Texas (USA). - Aquat Geochem 19: 173193.

[15] Kouba, A., Buric, M., Kozak, P. (2010): Bioaccumulation and effects of heavy metals in crayfish: a review. - Water Air Soil Pollut 211: 5-16.

[16] Li, Z., Shuman, L. M. (1997): Mobility of $\mathrm{Zn}, \mathrm{Cd}$ and $\mathrm{Pb}$ in soils as affected by poultry litter extract I. Leaching in soil columns. - Environ Pollut 95: 219-226.

[17] Noges, P., Tuvikene, L., Noges, T., Kisand, A. (1999): Primary production, sedimentation and resuspension in large shallow Lake Vortsjarv. - Aquat Sci 61: 168182.

[18] Nriagu, J. O., Pacyna, J. M. (1988): Quantitative assessment of worldwide contamination of air, water and soils by trace-metals. - Nature 333: 134-139.

[19] Ranville, J. F., Hendry, M. J., Reszat, T. N., Xie, Q. L., Honeyman, B. D. (2007): Quantifying uranium complexation by groundwater dissolved organic carbon using asymmetrical flow field-flow fractionation. - JContamHydrol 91: 233-246.

[20] Refaey, Y., Jansen, B., Parsons, J. R., de Voogt, P., Bagnis, S., Markus, A., El-Shater, A.H., El-Haddad, A.-A., Kalbitz, K. (2017): Effects of clay minerals, hydroxides, and timing of dissolved organic matter addition on the competitive sorption of copper, nickel, and zinc: A column experiment. - Journal of Environmental Management 187: 273-285.

[21] Ross, J. H., Dudel, E. G. (2008): Uranium loads and accumulation in a mine water contaminated wetland. - In: Rapantova, N., Hrkal, Z. (eds.) Mine Water and the Environment. Technical University of Ostrava, Ostrava, pp. 225-228.

[22] Sachs, S., Brendler, V., Geipel, G. (2007): Uranium (VI) complexation by humic acid under neutral $\mathrm{pH}$ conditions studied by laser-induced fluorescence spectroscopy. Radiochim Acta 95: 103-110.

[23] Schaller, J., Weiske, A., Mkandawire, M., Dudel, E. G. (2008): Enrichment of uranium in particulate matter during litter decomposition affected by Gammarus pulex L. - Environ Sci Technol 42: 8721-8726. 
[24] Schaller, J., Mkandawire, M., Dudel, E. (2010): Heavy metals and arsenic fixation into fresh water organic matter under Gammarus pulex L. influence. - Environ Pollut 158: 2454-2458.

[25] Schaller, J., Vymazal, J., Brackhage, C. (2013): Retention of resources (metals, metalloids and rare earth elements) by autochthonously/allochthonously dominated wetlands: A review. - Ecol Eng 53: 106-114.

[26] Wang, S., Mulligan, C. (2009): Enhanced mobilization of arsenic and heavy metals from mine tailings by humic acid. - Chemosphere 74: 274-279.

[27] Yamashita, Y., Jaffe, R. (2008): Characterizing the interactions between trace metals and dissolved organic matter using excitation-emission matrix and parallel factor analysis. Environ Sci Technol 42: 7374-7379.

[28] Yin, H. B., Gao, Y. N., Fan, C. X. (2011): Distribution, sources and ecological risk assessment of heavy metals in surface sediments from Lake Taihu, China. - Environ Res Lett 6: 044-012.

[29] Yuan, G., Liu, C., Chen, L., Yang, Z. (2011): Inputting history of heavy metals into the inland lake recorded in sediment profiles: Poyang Lake in China. - J Hazard Mater 185: 336-345.

[30] Zhao, L. Y. L., Schulin, R., Nowack, B. (2009): Cu and Zn mobilization in soil column spercolated by different irrigation solutions. - Environ Pollut 157: 823-833. 